\title{
The effect of work system on the hand exposure of workers in ${ }^{18} \mathrm{~F}-\mathrm{FDG}$ production centres
}

\author{
Małgorzata Wrzesień ${ }^{1}$ (1)
}

Received: 23 August 2017 / Accepted: 25 April 2018 / Published online: 7 May 2018

(c) The Author(s) 2018

\begin{abstract}
The production of the ${ }^{18} \mathrm{~F}$ isotope — the marker of deoxyglucose $\left({ }^{18} \mathrm{~F}-\mathrm{FDG}\right)$ - the radiopharmaceutical most commonly used in the oncological diagnostic technique of positron emission tomography, requires a cyclotron device. At present, there are nine facilities working in Poland that are equipped with cyclotrons used for producing the short-lived isotopes. The aim of the paper is to determine the hand exposure of workers employed in the two ${ }^{18} \mathrm{~F}-\mathrm{FDG}$ production centres taking in to account the production procedures and work system in those facilities. Measurements, which included all professional workers exposed to ionizing radiation that were employed in two facilities, were performed by using high-sensitivity thermoluminescent detectors during the routine activities of the personnel. The work system used at the production centre has an impact on the level of the recorded doses. Among the production procedures performed by the staff, the highest ionizing radiation doses have been received by the staff during the ${ }^{18} \mathrm{~F}-\mathrm{FDG}$ quality control. The maximum estimated annual $\mathrm{Hp}(0.07)$ for chemists from the quality control department can exceed the annual skin limit dose $(500 \mathrm{mSv})$. The source of lowest doses on the hands are the cyclotron operating procedure and the ${ }^{18} \mathrm{~F}-\mathrm{FDG}$ production, provided that these procedures can't be combined with other production procedures.
\end{abstract}

Keywords Radiopharmaceuticals $\cdot$ Work system $\cdot$ Nuclear medicine $\cdot$ Personnel exposure $\cdot$ Radiation protection

\section{Introduction}

${ }^{18} \mathrm{~F}$-labeled deoxyglucose $\left({ }^{18} \mathrm{~F}-\mathrm{FDG}\right)$, is in wide use in oncological diagnostics via positron emission tomography (PET) technique [1]. The production of ${ }^{18} \mathrm{~F}-\mathrm{FDG}$ is a multistep process that begins by obtaining the ${ }^{18} \mathrm{~F}$, and subsequently: labelling the radiopharmaceutical; preparing the individual ${ }^{18}$ F-FDG vial activity; quality control of the resulting compound; packaging the vials with radiopharmaceutical into shielded containers; and transportation of the produced compound to PET departments [2].

Currently in Poland, there are nine centres equipped with a cyclotron for the production of positron-emitting radioisotopes. Polish centres producing radiopharmaceuticals for the purpose of positron emission tomography can be divided taking into account commercial and non-commercial

Małgorzata Wrzesień

mwrzesien@uni.lodz.pl

1 Faculty of Physics and Applied Informatics, Department of Nuclear Physics and Radiation Safety, University of Lodz, Pomorska 149/153, 90-236 Lodz, Poland production. Non-commercial production means that the radiopharmaceuticals labeled with short-lived isotopes are solely for the purposes of a PET-CT diagnostic centre (located, in most cases, in the immediate vicinity of the production centre). Commercial production purpose also accounts for the needs of a diagnostic facility located in the immediate vicinity.

In both centre types, the personnel includes physicists, chemists and technical staff. However, in the case of ${ }^{18} \mathrm{~F}$ FDG production centres that operate solely for the needs of the nearest PET-CT departments only, nursing staff should also be taken into consideration. The publication presents an analysis of the personnel, as well as the working system in the ${ }^{18} \mathrm{~F}$-FDG production centres, in terms of hand exposure to ionizing radiation of the medical staff employed. This work complements the paper by Wrzesień [3] which examined the exposure of the eye lens of workers in radiopharmaceutical production centers. 


\section{Materials and methods}

Measurements were carried out in two ${ }^{18} \mathrm{~F}$-FDG production centres by using high-sensitivity thermoluminescent detectors (TLDs): LiF: $\mathrm{Mg}, \mathrm{Cu}, \mathrm{P}$ (MCP-N) [4, 5] produced by RADCARD. A gamma radiation source- $-{ }^{137} \mathrm{Cs}$ $\left({ }^{60} \mathrm{Co} /{ }^{137} \mathrm{Cs}\right.$ irradiator) was used to calibrate the detectors in the Secondary Standards Laboratory in Nofer Institute of Occupational Medicine in Lodz. Dosimeters were calibrated in accordance with ISO 4037-3 [6] in the range from 0.05 to $30 \mathrm{mGy}$ as the air kerma. The $\mathrm{H}_{\mathrm{p}}(0.07)$ for fingers was calculated taking into account the conversion coefficient $h_{\mathrm{pK}}(0.07)$, given in the ISO International Standard. We used the rod phantoms [7]. The readings of the dosimeters were read out using an RA ' 04 reader from Mikrolab Co.

Measurements were carried out during routine work of the staff in both departments. In the case of the production centre marked RPC I, which produces ${ }^{18} \mathrm{~F}$-FDG essentially for commercial purposes, the structure of employment is dominated by a clear division, which in turn is dictated by production procedures performed in the facility. The measurements were carried out for three groups of employees: operators of a cyclotron (two physicists), production workers (three chemists), and quality control staff (two chemists).

Measurements were performed in the span of 3 weeks. The production process at the facility takes place from Monday to Thursday, which represented a total of 11 measurement days. The production, depending on the number of orders, included one or two production runs (shifts) which meant that, during the 11 days of measuring, the ${ }^{18} \mathrm{~F}$-FDG was produced 19 times. One shift (production run) represents one vial of the finished product that goes to the quality control laboratory [3]. The activities performed by production workers included the placement of a vial in a synthesizer; the vials were automatically filled with the final radiopharmaceutical product [3].

In the case of the facility producing ${ }^{18} \mathrm{~F}$-FDG solely for the needs of a neighboring PET-CT department (marked RPC II), the structure of employment is no longer so heavily dominated by the production procedures carried out in the facility. Here, it is generally easier to distribute the employees based on their specialty training (education). Measurements have covered four chemists, two physicists and four nurses. The task of the physicists was the daily supervision of the proper functioning of the cyclotron. The nurses inject the ${ }^{18} \mathrm{~F}-\mathrm{FDG}$ to the patients in the activity prescribed by the medical doctor. For the chemists, the division of work tasks is not as clearly defined, because the staff were trained so that, in the event of an absence of a worker, another may cover their tasks. This means that, in contrast to the first facility, in the group of chemists, procedures are not strictly assigned to individual people. Thus, all the procedures: production, quality control, and dispensing the dose of radiopharmaceutical for an individual patient at the facility can be done by one person. The production of ${ }^{18} \mathrm{~F}-\mathrm{FDG}$ is carried out in the facility three times a week. The measurements were performed during the 11 days of work.

From the point of view of the occupational structure of the workers employed in RPC II, Chemist 1 performs only the combined procedures of the production and dispensing of doses of ${ }^{18} \mathrm{~F}$-FDG for patients; alternatively, in addition to the above procedures, quality control of the radiopharmaceutical is carried out as well. Chemist 2 performs only the ${ }^{18}$ F-FDG quality control procedures or combines all three procedures- ${ }^{18} \mathrm{~F}$-FDG production, quality control and dispensing doses of ${ }^{18} \mathrm{~F}$-FDG for patients. Chemist 3 performs three production procedures or carries out only the procedure for dispensing doses of ${ }^{18} \mathrm{~F}-\mathrm{FDG}$ for individual patients. And the last in the group of chemists from the center RPC II-Chemist 4 performs only the procedure of dispensing doses of ${ }^{18} \mathrm{~F}$-FDG for patients during the second shift. The work specificity of RPC II means that the personnel also includes nurses working in shifts.

Before the measurements, the detectors were annealed in accordance with the manufacturer's guidelines and each of them was individually vacuum packed in foil. Thus prepared detectors were placed at the fingertips of the left and right hand and also in a standard ring dosimeter location (both hands) as shown in Fig. 1.

The statistical analysis was performed using the Mann-Whitney test and applying STATISTICA v. 10.0 MR1 software. Any differences found was considered statistically significant if $\mathrm{p}$ value was below 0.05 .

\section{Results}

\section{Personnel in radiopharmaceutical production centres (RPC)}

Figure 2 presents the values of $\operatorname{Hp}(0.07)$ recorded during one working day on the hands of staff employed in radiopharmaceutical production centres, taking into account the professional position of workers.

The greatest differences of $\mathrm{Hp}(0.07)$ values recorded during one working day relate to the chemists, in particular those employed in RPC II. This is due to the diversity and spread of production procedures carried out by the same people representing that professional group. This means, therefore, a detailed analysis of individual production procedures carried out in both production facilities taking into account the structure of employment is required. 

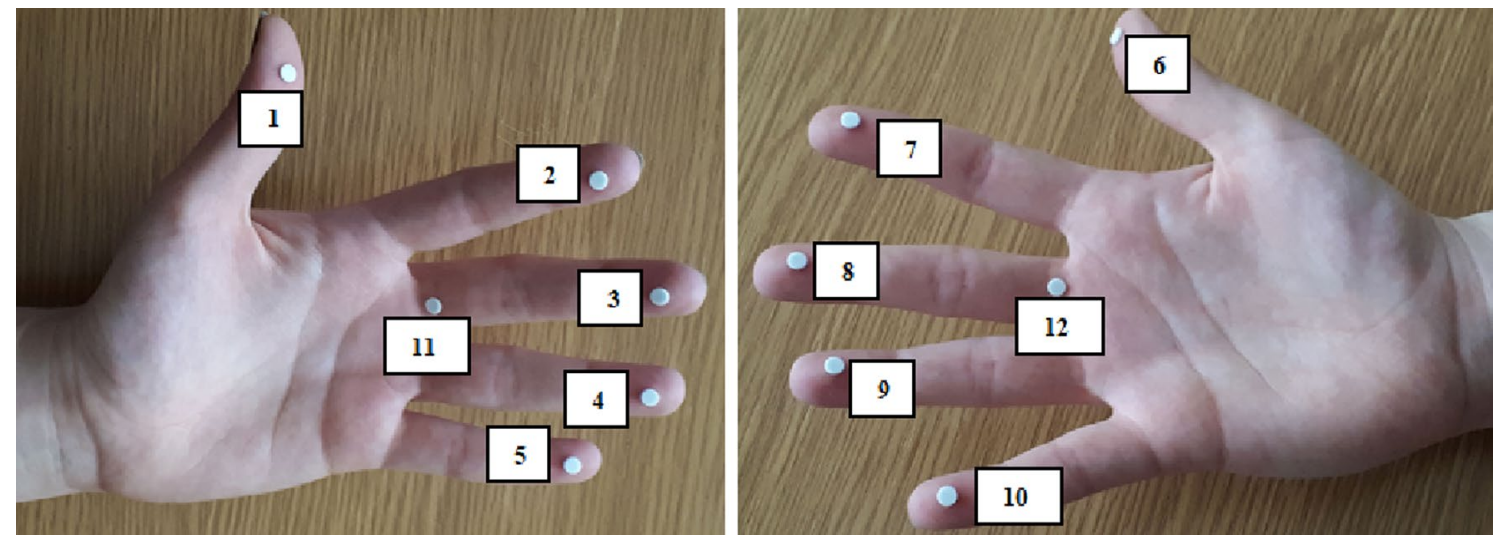

Fig. 1 Location of TLDs on worker's hand. Points ' 11 ' and '12' denote points placed at the base of the middle finger of the left and right worker's hands and corresponding the standard ring dosimeter location

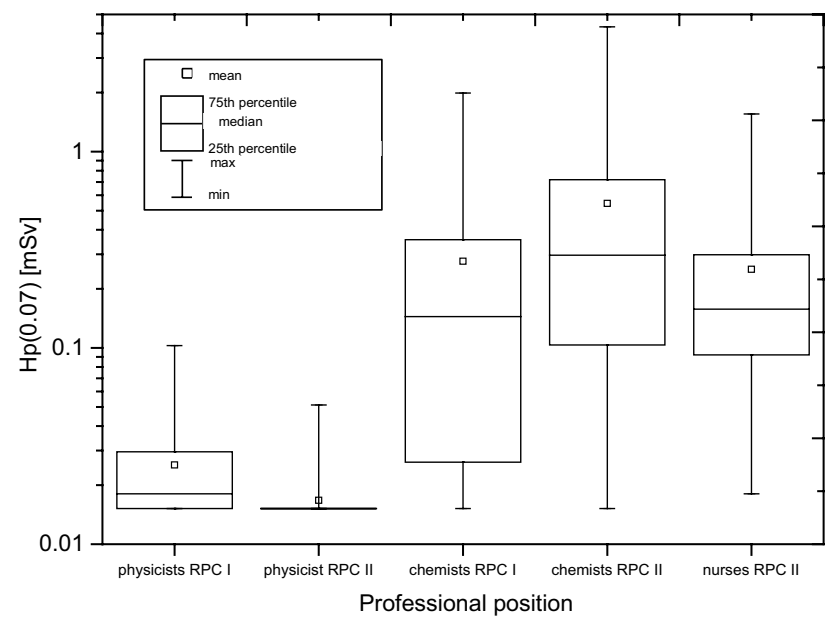

Fig. 2 The $\mathrm{Hp}(0.07)$ recorded during one working day on hands of the staff employed in radiopharmaceutical production centres, taking into account the professional position of workers. RPCI, RPCII denote, respectively, Radiopharmaceutical Production Centre I and II

\section{Hand exposure during ${ }^{18} \mathrm{~F}-\mathrm{FDG}$ production procedures}

Figure 3 presents mean working-day values of $\mathrm{Hp}(0.07)$ for staff who performed ${ }^{18} \mathrm{~F}$-FDG production procedures in RPC I and RPC II, taking into account the professional position of workers.

The highest values of $\mathrm{Hp}(0.07)$ recorded during one working day involve basically the chemists employed in RPC II. Chemists (1, 2 and 3) employed in RPC I, are performing only the ${ }^{18} \mathrm{~F}$-FDG production procedures. In RPC II, employed chemists were performing mostly "cumulative" production procedures, which means that one chemist can perform two or even three radiopharmaceuticals production procedures. During the measurements the Chemist 1, Chemist 2 and Chemist 3 employed in RPC II were performing

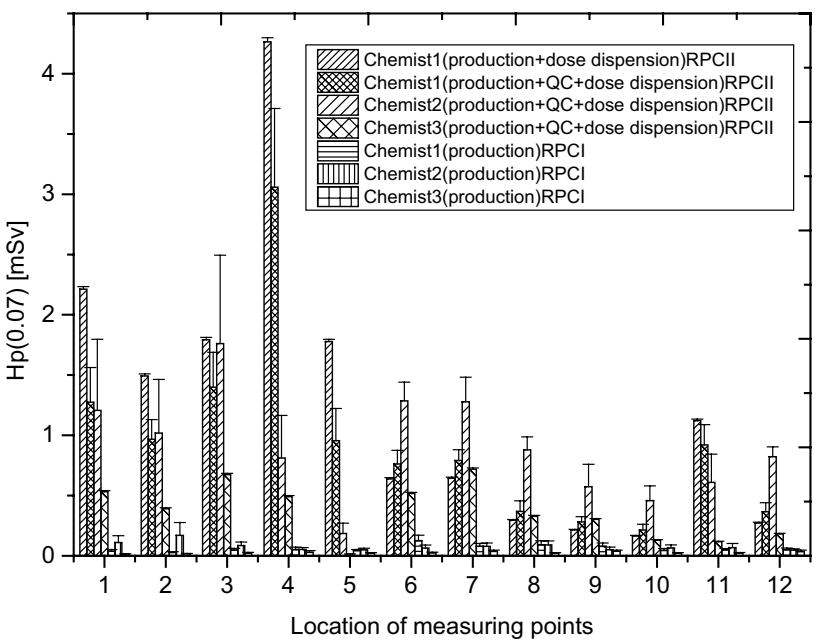

Fig. 3 The mean working-day values of $\mathrm{Hp}(0.07)$ for staff who performed ${ }^{18} \mathrm{~F}-\mathrm{FDG}$ production procedures in RPC I and RPC II, taking into account the professional position of workers

cumulative procedures, including ${ }^{18} \mathrm{~F}$-FDG production and dispensing doses of the radiopharmaceutical, or they jointly performed all three production procedures $\left({ }^{18} \mathrm{~F}-\mathrm{FDG}\right.$ production, quality control and dispensing doses for patients). The maximum value of $\mathrm{Hp}(0.07)$ recorded during one working day for Chemist 1 employed in RPC II, who performed cumulative procedures including the production, quality control and dispensing of doses of the radiopharmaceutical was: $4.32 \pm 0.07 \mathrm{mSv}$ (for tip of the ring finger of the non-dominant, left hand). In the case of the same worker (Chemist 1), who performed two production procedures $\left({ }^{18} \mathrm{~F}-\mathrm{FDG}\right.$ production, and dispensing dose of radiopharmaceutical for patients) and additionally in the same measuring point, the highest value of $\mathrm{Hp}(0.07)$ recorded during one working day was $4.26 \pm 0.03 \mathrm{mSv}$. There are no statistically significant differences between the distributions of 
$\mathrm{Hp}(0.07) / \mathrm{A}$ (normalized value of $\mathrm{Hp}(0.07)$ to the activity of ${ }^{18} \mathrm{~F}-\mathrm{FDG}$ ) recorded for Chemist 1 during two production procedures including ${ }^{18} \mathrm{~F}$-FDG production and dispensing doses of radiopharmaceutical, and all three production procedures being performed together. At the same time, comparing the distributions of $\mathrm{Hp}(0.07) / \mathrm{A}$ registered during one working day for three chemists carrying out a total of three production procedures $\left({ }^{18} \mathrm{~F}-\mathrm{FDG}\right.$ production, quality control and dispensing dose of radiopharmaceutical for patients), there was no statistically significant difference. In the case of the RPC I staff-chemists, who perform only the ${ }^{18}$ F-FDG production procedure, a statistically significant difference exists between the distribution of $\mathrm{Hp}(0.07)$ recorded within one working day for Chemist 2 and $3(p=0.000037)$ and Chemist 3 compared with Chemist $1(\mathrm{p}=0.000097)$. Such a difference is not found between the distributions of values $\mathrm{Hp}(0.07)$ obtained for Chemist 1 and $2(\mathrm{p}=0.14)$. In this case the individualized activities performed by individual chemists especially Chemist 3 may influence on the level of the $\mathrm{Hp}(0.07)$.

\section{Hand exposure of quality control workers from the shift (production run) point of view}

The shift-based working system in the first production facility (RPC I) makes it possible to check the influence of the order of the shifts of quality control employees on the level of the recorded dose.

Figure 4 shows that the trend of the higher fingertips exposure during the second shift is preserved only for the Chemist 5. In the case of the Chemist 4, the fingertips of the left hand (except the little finger) receive higher doses during the first working shift. The most important factor in

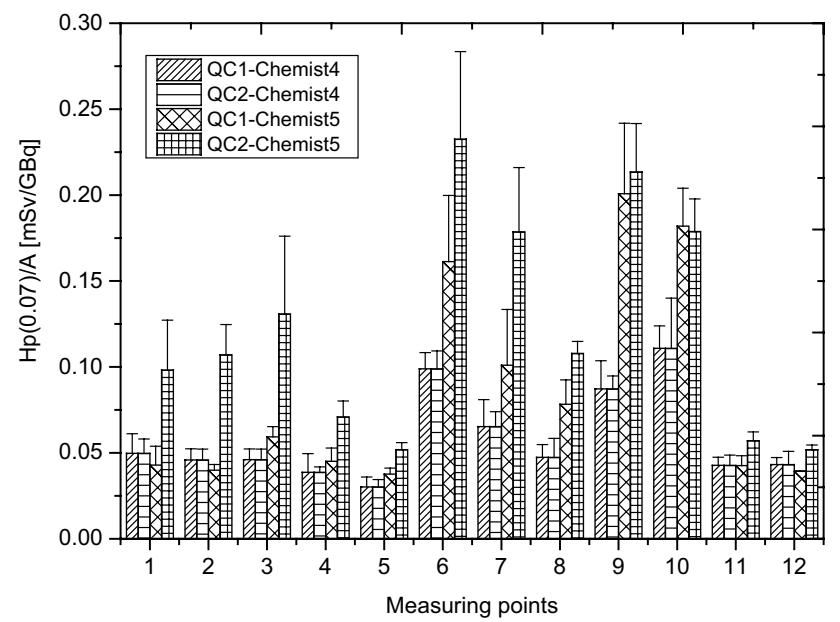

Fig. 4 The average values of $\mathrm{H}_{\mathrm{p}}(0.07) / \mathrm{A}$ for quality control staff taking into account the production run. QC1 and QC2 denoted the order of the shift (production run) in radiopharmaceuticals quality control department this case seems to be the activity of the radiopharmaceutical forwarded to the quality control department. During the first shift, the average ${ }^{18} \mathrm{~F}$-FDG activity was $6.4 \mathrm{GBq}$, for employees of the second shift it was $6.7 \mathrm{GBq}$ [2].

In the production facility RPC II, there is no clear assignment of the employee to a specific production procedure; however, it was possible to isolate the quality control procedure in the case of one employee. The comparison of average values $\mathrm{Hp}(0.07)$ normalized by the activity in the case of employees of the quality control lab in two production centres is shown in Fig. 5.

It is worth noting that the highest $\mathrm{Hp}(0.07) / \mathrm{A}$ was recorded for the worker from RPC II-centre, which produces the ${ }^{18}$ F-FDG solely for the use of a neighboring PETCT department.

Even though the quality control procedures of radiopharmaceuticals produced in both production centres are similar, the mean values of $\mathrm{Hp}(0.07)$ normalized by activity, particularly in the case of the left hand of RPC II worker, are at least one order of magnitude higher compared to the two workers from RPC I.

\section{Hand exposure of workers performing the cyclotron operators procedures against the professional position}

Operating of the cyclotron is a procedure during which the values of $\mathrm{Hp}(0.07)$ for employees from the RPC I are, on average, higher than those recorded by the detectors placed on the hands of the staff from RPC II who performed the same procedure (Fig. 6). In terms of the task associated with the operation of the cyclotron, the activities carried out by

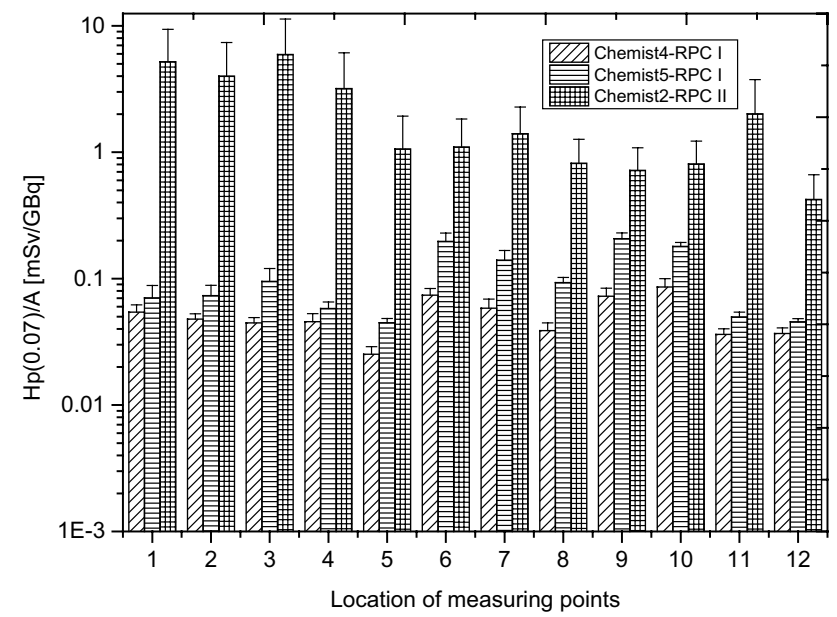

Fig. 5 Distribution of mean values of $\mathrm{Hp}(0.07) / \mathrm{A}$ on the left and right hand two employees of the quality control department at RPC I and one employee in RPC II 


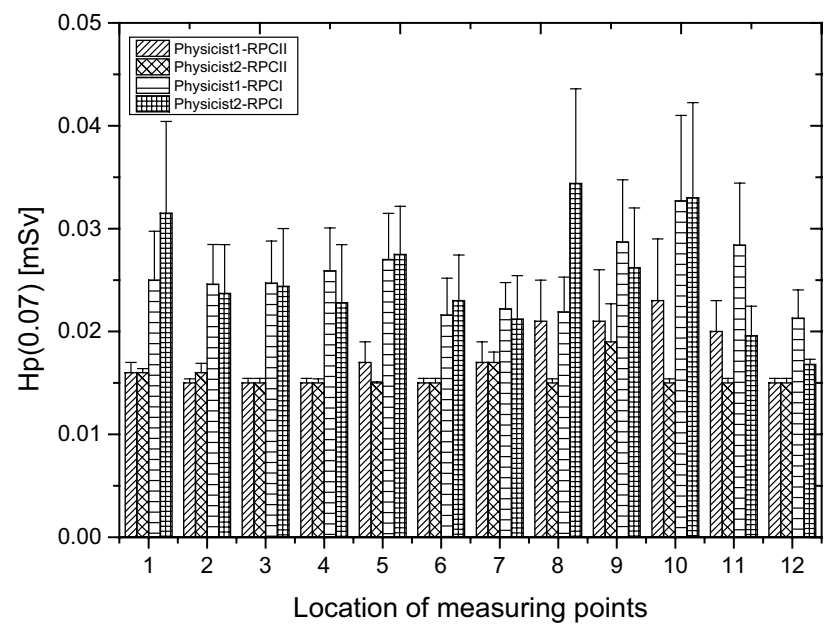

Fig. 6 Mean values of $\mathrm{Hp}(0.07)$ recorded by the individual measuring points of cyclotron operating personnel in both radiopharmaceuticals production centres

physicists working in RPC II and physicists from the RPC I are different.

\section{Hand exposure of workers during dispensing doses of ${ }^{18} \mathrm{~F}$-FDG for patients and injection radiopharmaceuticals to the patients}

Individual dispensing of doses of ${ }^{18} \mathrm{~F}$-FDG for patients was performed by two chemists. Figure 7 presents the mean values $\mathrm{Hp}(0.07) /$ A for the two chemists performing only the dispensing doses of ${ }^{18} \mathrm{~F}-\mathrm{FDG}$ for patients and three nurses

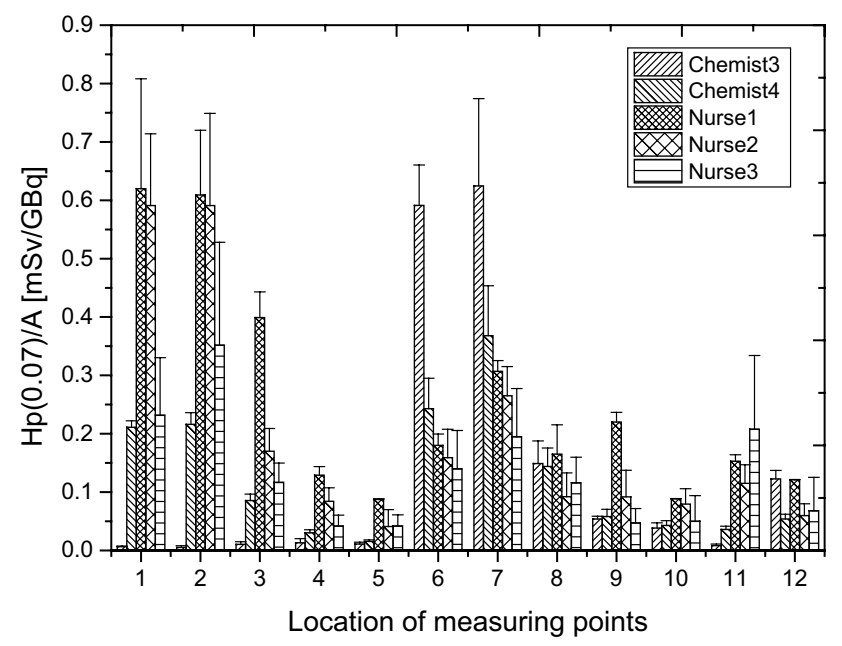

Fig. 7 Mean values $\mathrm{Hp}(0.07) / \mathrm{A}$ recorded by the individual measuring points of chemists who dispense doses of ${ }^{18} \mathrm{~F}$-FDG for patients and nurses performing injection of the radiopharmaceutical. All workers are employees in RPC II performing the injection of ${ }^{18} \mathrm{~F}-\mathrm{FDG}$ to the patients. All workers are employees in the RPC II.

The statistically significant difference between the distributions of normalized $\mathrm{Hp}(0.07)$ obtained during one working day for Chemist 3 and 4 for measuring point 1, 2 and 3 and also 11 and 12 was found $(\mathrm{p}=0.018904)$. Comparing the distributions of mean values of $\mathrm{Hp}(0.07) / \mathrm{A}$ for chemists and nurses, a statistically significant difference was found for Chemist 3 and Nurse $1(\mathrm{p}=0.014138)$ and Chemist 4 and Nurse $1(\mathrm{p}=0.035090)$. Nurse 1 employed at RPC II works ad hoc solely in case of the absence of Nurse 2 or 3 . It is true that differences in the distributions of $\mathrm{Hp}(0.07) / \mathrm{A}$ recorded for three nurses can be seen primarily in the case of the tip of the thumb, as well as index and middle fingers of the left hand.

The data for Chemist 3 and 4 during the dispensing of doses of ${ }^{18} \mathrm{~F}$-FDG for patients was compared with the data from another diagnostic department, where this procedure is realized by a physicist. The total daily ${ }^{18} \mathrm{~F}-\mathrm{FDG}$ activity prepared for patients by a physicist is in the range 0.68-2.52 GBq and in the case of chemists: $0.83-3.12 \mathrm{GBq}$. Figure 8 shows the distribution of $\mathrm{Hp}(0.07) / \mathrm{A}$ recorded by TLD at the fingertips of the left hands and right hands during the dispensing of doses of ${ }^{18} \mathrm{~F}$-FDG for patients carried out by chemists working in the center RPC II and physicist employed in the Medical Diagnostic Centre (MDC) in Lodz provided with PET/CT unit [8].

The average number of patients diagnosed during 1 day in two centres is similar (ten patients), the value of the ${ }^{18} \mathrm{~F}$ FDG activity dispensed for a single patient is also approximately the same.

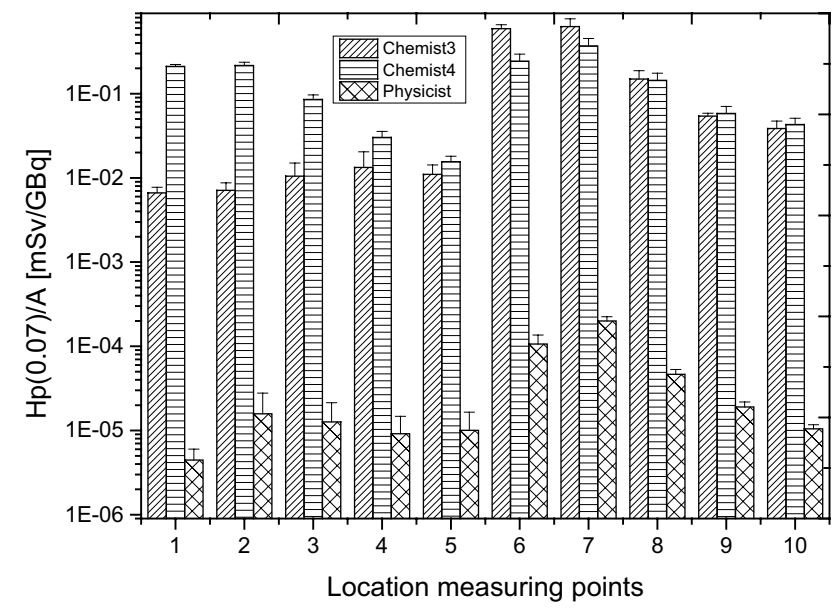

Fig. 8 Distribution of $\mathrm{Hp}(0.07) / \mathrm{A}$ recorded by TLD placed at the fingertips of the left hand and right hand during the dispensing doses of ${ }^{18} \mathrm{~F}$-FDG for patients carried out by the chemists employed in the RPC II center and physicist employed in Medical Diagnostic Centre (MDC) 


\section{Estimated annual dose for the workers in ${ }^{18}$ F-FDG production centres}

In the case of employees of RPC I, the maximum annual $\mathrm{Hp}(0.07)$ was estimated assuming the implementation of 300 production procedures, taking into account only the most exposure fingertips. Annual fingers exposure to ionizing radiation in case of RPC II employees, was estimated taking into account the nature of professional's work. It was assumed that ${ }^{18} \mathrm{~F}$-FDG production took place three times a week (120 working days a year in total). Estimated values are presented in Table 1.

\section{Discussion}

The production of radiopharmaceuticals based on short-lived isotopes arouses much interest from the point of view of exposure of personnel performing various production procedures despite the automation of some production procedures. Exposure of personnel in nuclear medicine facilities during the labeling of radiopharmaceuticals by using even ${ }^{99 \mathrm{~m}} \mathrm{Tc}$ shows that the main source of exposure of personnel is the same process of radiopharmaceuticals labeling [9]. The ORAMED project $[10,11]$ discusses in detail the exposure of medical personnel performing procedures using the isotope ${ }^{18} \mathrm{~F}$ as well. In this case, however, it analyzed the exposure of workers performing manual procedures of labeling the radiopharmaceuticals. The exposure of workers from two ${ }^{18} \mathrm{~F}-\mathrm{FDG}$ production centers discussed in the paper, taking into account both the professional position, as well as the specificity of the work in the facility, suggests that in this area there are also issues that require careful analysis, taking into account the work system of production centres.

The RPC I implements the philosophy of ${ }^{18}$ F-FDG production based on the assignment of specific procedures for employees while taking into account the shift working system. This means that the person performing the various

Table 1 Maximum estimated annual $\mathrm{Hp}(0.07)$ for the staff employed in RPC I and RPC II

\begin{tabular}{lc}
\hline Professional groups/RPC & $\begin{array}{l}\text { Maximum estimated } \\
\text { annual } \mathrm{Hp}(0.07)(\mathrm{mSv})\end{array}$ \\
\hline Physicists/RPC I & 11 \\
Chemists/RPC I & 445 \\
Physicists/RPC II & 3 \\
Chemists/RPC II & $\mathbf{5 1 2}$ \\
Nurses/RPC II & 135 \\
\hline
\end{tabular}

A bold font was used to emphasize that the maximum estimated annual $\mathrm{Hp}(0.07)$ for chemists from the quality control department exceed the annual skin limit dose- $500 \mathrm{mSv}$ procedures involving cyclotron operation, ${ }^{18} \mathrm{~F}$-FDG production and quality control of the finished radiopharmaceutical, varies depending on the order of duty resulting from a schedule roster. In the RPC II, producing ${ }^{18} \mathrm{~F}-\mathrm{FDG}$ solely for the purpose of a PET-CT diagnostic department, located mostly in the immediate vicinity of the production centre, each employee has been trained for the implementation of all procedures, so that, if necessary, they can perform any of the required production procedures. Here, however, the shift working system included only Chemist 3 and Chemist 4. Hence Chemist 4 as the only worker from the chemists group performs the dispensing of doses of ${ }^{18} \mathrm{~F}$-FDG for the patients, and doing this only during the second shift. Figure 3 seems to confirm the assumption that specializing in carrying out specific activities optimizes radiation protection of personnel and helps reduce the doses of ionizing radiation.

It seems that the working system based on the combined radiopharmaceutical production procedures implemented in RPC II, compared to the RPC I should be a source of higher $\mathrm{Hp}(0.07)$ for the personnel performing only the procedure of ${ }^{18} \mathrm{~F}$-FDG production or quality control of the radiopharmaceutical. The explanation of this fact seems simple: performing the same manipulations during a single procedure, every single day, results in higher efficiency and thus shortens the time performing the procedure. The only case when the recorded value of $\mathrm{Hp}(0.07)$ at all measurement points for the staff of the RPC I are higher in comparison with the RPC II concerns the cyclotron operating procedure. The tasks of chemists from the RPC I, in addition to the daily supervision of the proper functioning of the cyclotron and the replenishment of water enriched in ${ }^{18} \mathrm{O}$, includes the preparation of the tungsten containers containing the product ready to leave the centre. This is another example of an increased dose during the implementation of a greater number of procedures using the radiopharmaceutical (even if the radiopharmaceuticals are covered by tungsten).

Dispensing doses of ${ }^{18} \mathrm{~F}-\mathrm{FDG}$ for patients according to the value specified by the medical doctor in a second production centre (RPC II) is also performed by chemists (two persons). Hand exposure of both employees looks different, as a consequence of differences relating to the way they work. Chemist 4 uses both hands when dispensing doses of ${ }^{18} \mathrm{~F}$-FDG for the patient, as shown in particular in points $1-5$ (Fig. 7). In the case of Chemist 3, if it is possible to perform the same procedure by using only one hand, the procedure is carried out just like that. This way of working reliably minimizes the exposure of the non-dominant hand. However, it affects the rate of actions and increases the exposure of the dominant hand. The data for Chemist 3 and 4 during the dispensing of doses of ${ }^{18} \mathrm{~F}$-FDG for patients was also compared with the data from another diagnostic department, 
where this procedure is realized by a physicist. The results are shown in Fig. 8.

The procedure of filling up the syringe ${ }^{18} \mathrm{~F}$-FDG with activity occurs automatically. Similarities also arise in which fingertips are the most exposed: the thumb and index finger of the right hand while performing this procedure. Despite these similarities, the difference between the $\mathrm{Hp}(0.07) / \mathrm{A}$ for the thumb and index finger of the right hand for employees RPC II and MDC is, on average, three orders of magnitude. These differences can be explained by an individualization of manipulations and, above all, the time it takes to perform these.

Measurements performed in both centres also allow us to determine which of the activities/procedures carried out by the staff of both units contributes the most to the recorded dose. In the case of the RPC I, the greatest contribution to the dose recorded by TLD placed on the fingertips ( $80 \%$ for the left hand, and $89 \%$ for the right hand) is by the quality control of the radiopharmaceutical. The case of RPC II is similar. Here, the percentage of radiopharmaceutical quality control procedures for the left hand is over $96 \%$; for the right hand, it is $83 \%$.

\section{Conclusions}

The measurements performed allow us to reach the following conclusions. The work system undoubtedly affects the level of recorded doses; specialization in performing specific activities/procedures shortens the time of performed procedures, which in turn results in lower doses. Automatic production of ${ }^{18} \mathrm{~F}-\mathrm{FDG}$ promotes the optimization of radiation protection of personnel. Combining automatically performed production procedures with fragments of manual activities performed as part of the quality control of the radiopharmaceutical results in increased of hand exposure.

The highest ionizing radiation doses have been received by the staff during the ${ }^{18} \mathrm{~F}-\mathrm{FDG}$ quality control. Hand exposure of nurses performing the administration of radiopharmaceuticals to the patient is different from the exposure of the hands of the chemists who dispensed the doses of ${ }^{18} \mathrm{~F}-$ FDG for patients. The source of lowest doses on the hands are the cyclotron operating procedure and the ${ }^{18} \mathrm{~F}-\mathrm{FDG}$ production, provided that these procedures can't be combined with other production procedures.

The maximum estimated annual $\mathrm{Hp}(0.07)$ for chemists from the quality control department employed in RPC I does not exceed $445 \mathrm{mSv}$. For the physicists from RPC I, it will not exceed $11 \mathrm{mSv}$. In the case of workers employed in RPC II, the maximum annual equivalent dose was estimated in the group of chemists $-512 \mathrm{mSv}$. In the group of nurses it will reach up to $27 \%$ of the annual limit, while in the group of physicists, it will not exceed $0.6 \%$ of the annual dose limit, which is $500 \mathrm{mSv}$ [12].

Acknowledgements The author would like to warmly thank all the people from the Radiopharmaceuticals Production Centres for their help in collecting these data. This research was financially supported by the Ministry of Science and Higher Education of Poland, project number B 1411500000542.02 and B 1611500001135.02.

\section{Compliance with ethical standards}

Conflict of interest The author declares that there is no conflict of interest.

Ethical approval All procedures performed in studies involving human participants were in accordance with the ethical standards of the institutional and/or national research committee and with the 1964 Helsinki declaration and its later amendments or comparable ethical standards. This article does not contain any studies with animals performed by any of the authors.

Informed consent Informed consent was obtained from all individual participants included in the study.

Open Access This article is distributed under the terms of the Creative Commons Attribution 4.0 International License (http://creativeco mmons.org/licenses/by/4.0/), which permits unrestricted use, distribution, and reproduction in any medium, provided you give appropriate credit to the original author(s) and the source, provide a link to the Creative Commons license, and indicate if changes were made.

\section{References}

1. Królicki L, Kunikowska J, Kobylecka M, Mączewska J, Fronczewska K (2011) Positron emission tomography (PET) in diagnosis of oncological diseases. Prog Med Sci 2:104-108

2. Wrzesień M, Albiniak $€$ (2016) Hand exposure of workers in ${ }^{18} \mathrm{~F}$ FDG production centre. J Radiol Prot 36:N67-N76

3. Wrzesień $\mathrm{M}(2018) .{ }^{18} \mathrm{~F}$-FDG production procedures as a source of eye lens exposure to radiation. J Radiol Prot 38:382-393. https ://doi.org/10.1088/1361-6498/aaa287

4. Niewiadomski T, Bilski P, Budzanowski M, Olko P, Ryba E (1996) Progress in thermoluminescent dosimetry for radiation protection and medicine. Nukleonika 41(2):93-104

5. Bilski P (2002) Lithium fluoride: from LiF:Mg,Ti to $\mathrm{LiF}: \mathrm{Mg}, \mathrm{Cu}, \mathrm{P}$. Radiat. Prot Dosim 100:199-206. https://doi.org/10.1093/oxfor djournals.rpd.a005847

6. International Organization for Standardization (ISO) (1999) X and gamma reference radiation for calibrating dosemeters and doserate meters and determining their response as a function of photon energy. Part 3: Calibration of area and personal dosemeters and the measurement of their response as a function of energy and angle of incidence. International Standard ISO- 4037-3, Geneva

7. International Organization for Standardization, (2000) Nuclear energy — radiation protection-individual thermoluminescence dosemeters for extremities and eyes ISO Report 12794. ISO, Geneva

8. Wrzesień M, Napolska K (2015) Investigation of radiation protection of medical staff performing medical diagnostic examinations by using PET/CT technique. J Radiol Prot 35:197-207. https://doi. org/10.1088/0952-4746/35/1/197 
9. Wrzesień M (2018) Simplicity or complexity of the radiopharmaceutical production process in the light of optimization of radiation protection of staff $-{ }^{99 \mathrm{~m}} \mathrm{Tc}$ versus ${ }^{18} \mathrm{~F}$. Medycyna Pracy 69(3):(Polish). https://doi.org/10.13075/mp.5893.00687

10. Carnicer A, Sans-Merce M, Baechler S, Barth I, Donadille L, Ferrari P, Fulop M, Ginjaume M, Gualdrini G, Krim S, Mariotti M, Ortega X, Rimpler A, Ruiz N, Vanhavere F (2011) Hand exposure in diagnostic nuclear medicine with ${ }^{18} \mathrm{~F}$ - and ${ }^{99 \mathrm{~m}} \mathrm{Tc}$-labelled radiopharmaceuticals-Results of the ORAMED project. Radiat Meas 46:1277-1282. https://doi.org/10.1016/j.radmeas.2011.07.019
11. Vanhavere F, Carinou E, Gualdrini G, Clairand I, Sans Merce M, Ginjaume M, Nikodemova D, Jankowski J, Bordy J-M, Rimpler A, Wach S, Martin P, Struelens L, Krim S, Koukorava C, Ferrari P, Mariotti F, Fantuzzi E, Donadille L, Itié C, Ruiz N, Carnicer A, Fulop M, Domienik J, Brodecki M, Daures J, Barth I, Bilski P. (2012) Optimization of radiation protection of medical staff EURADOS Report 2012-02 Braunschweig

12. EURATOM Basic Safety Standard (BSS) Directive 2013/59 